 \\ ERNEST DRLANDD LAWRENCE BERKELEY NATIDNAL LABDRATIRY CONF-9708157--
}

Energy Efficient Alternative to Halogen Torchieres

Michael Siminovitch, Linsey Marr, Jeffery Mitchell, and Erik Page

Environmental Energy

Technologies Division

March 1997

Presented at the IESNA 1997 Annual Conference, Seattle, Washington, August 17-20, 1997, and to be published in the Proceedings

\section{RECEIVED \\ FFR $1 / 1998$ \\ OSTI}

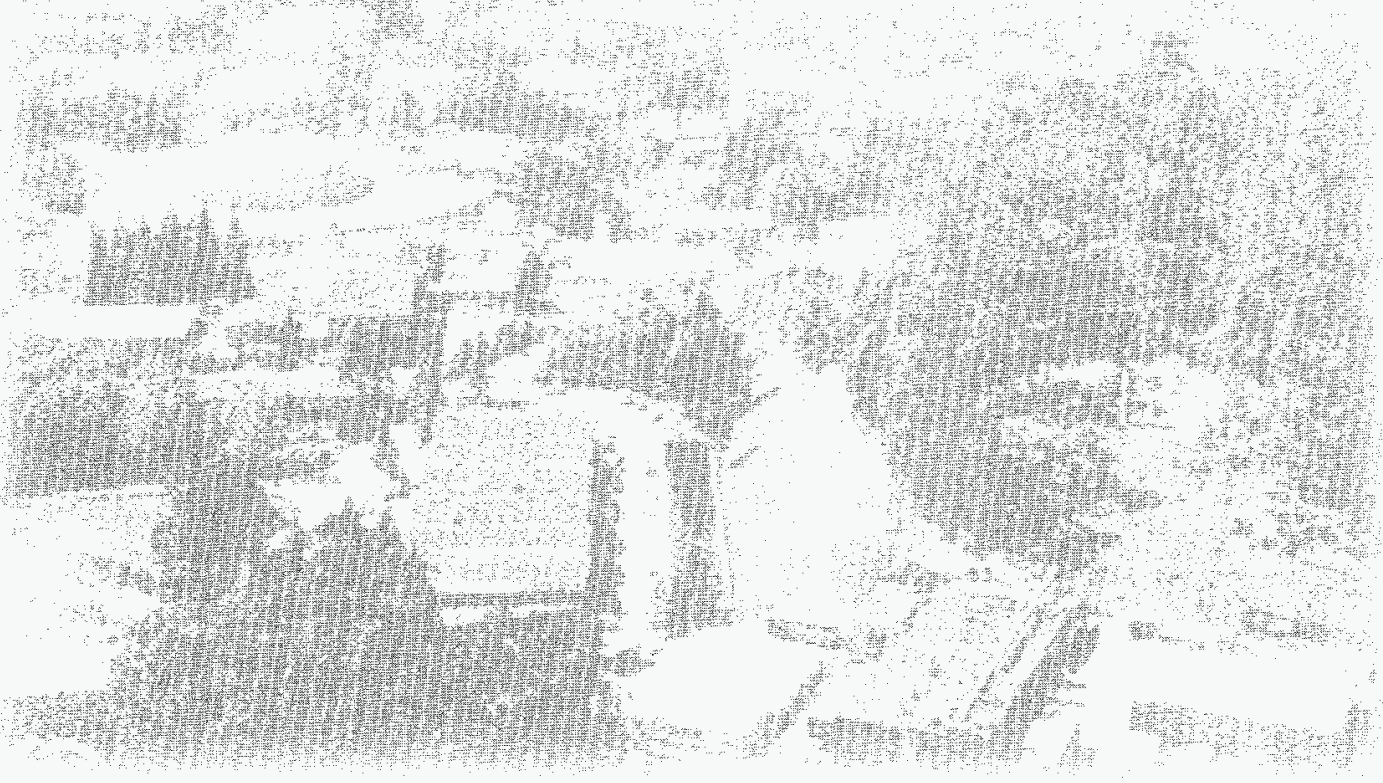

DISTAIBUTION OF THS DOCMENT IS UNLMTEO 


\section{DISCLAIMER}

This document was prepared as an account of work sponsored by the United States Government. While this document is believed to contain correct information, neither the United States Government nor any agency thereof, nor The Regents of the University of California, nor any of their employees, makes any warranty, express or implied, or assumes any legal responsibility for the accuracy, completeness, or usefulness of any information, apparatus, product, or process disclosed, or represents that its use would not infringe privately owned rights. Reference herein to any specific commercial product, process, or service by its trade name, trademark, manufacturer, or otherwise, does not necessarily constitute or imply its endorsement, recommendation, or favoring by the United States Government or any agency thereof, or The Regents of the University of California. The views and opinions of authors expressed herein do not necessarily state or reflect those of the United States Government or any agency thereof, or The Regents of the University of California.

Ernest Orlando Lawrence Berkeley National Laboratory is an equal opportunity employer. 


\section{DISCLAIMER}

Portions of this document may be illegible electronic image products. Images are produced from the best available original document. 
Presented at the IESNA 1997 Annual Conference, August 17-20, 1997, Seattle, WA, and to be considered for publication in the Journal of the IES.

\title{
Energy Efficient Alternative to Halogen Torchieres
}

\author{
Michael Siminovitch, Linsey Marr, Jeffery Mitchell, and Erik Page \\ Lighting Systems Research Group \\ Building Technologies Program \\ Environmental Energy Technologies Division \\ Lawrence Berkeley National Laboratory \\ University of California \\ Berkeley, CA 94720
}

March 1997

This work was supported by the Assistant Secretary for Energy Efficiency and Renewable Energy, Office of Building Technology, State and Community Programs, Office of Building Equipment of the U.S. Department of Energy under Contract No. DE-AC03-76SF00098. 


\title{
Energy Efficient Alternative to Halogen Torchieres
}

\author{
Michael Siminovitch, Linsey Marr, Jeffery Mitchell, and Erik Page \\ Lighting Systems Research Group \\ Lawrence Berkeley National Laboratory
}

\begin{abstract}
A series of novel energy efficient torchiere systems have been developed using compact fluorescent lamps (CFLs). These systems were studied photometrically and compared with the performance of traditional commercially available tungsten halogen sources. Gonio-photometric data and power assessments indicate that significant lighting energy savings can be obtained by utilizing CFL sources instead of standard tungsten halogen sources. This energy savings is jointly due to the higher source efficacy of the CFLs and the surprisingly poor performance of the imported 300 Watt halogen lamps. Experimental data shows that a 50 to 60 Watt CFL will effectively lumen match a variety of 300 Watt tungsten halogen sources with 5 to 10 times the efficacy. CFL torchieres have additional benefits of higher power quality and cooler lamp operating temperature, making them safer fixtures. ${ }^{1,2}$
\end{abstract}

\section{BACKGROUND}

Currently the American market is seeing a significant increase in sales of imported torchiere systems. These indirect lighting systems use tungsten halogen sources in the 300 to 500 Watt range. There are an estimated 40 million torchieres currently in the US stock with 15 to 18 million units in annual sales. ${ }^{3}$ Such wide usage of these systems has resulted in one of the largest increases in US residential lighting energy use and also represents a significant challenge to past and ongoing energy conservation programs throughout the country. Recent studies estimate that halogen torchieres now consume more energy than all of the CFLs are saving in the United States. ${ }^{4,5}$

This is particularly disheartening considering the level of resources federal and state programs have invested to accelerate the penetration of CFL technologies. Furthermore, many utilities throughout the country have sponsored rebate and incentive programs for years to accelerate market transformation with the CFL as one of the most effective conservation technologies. We are currently seeing the complete erosion of the progress associated with many of these demand-side management (DSM) activities.

In order to counter this conservation erosion, it is now necessary to rapidly research and develop energy efficient alternatives to the halogen torchiere fixture using compact fluorescent systems. To this end, a series of torchiere systems using efficient CFL sources were photometrically optimized. These studies are intended to provide information to manufacturers on how to use efficient sources as a replacement for the 300 Watt tungsten halogen source. This effort is part of an ongoing program that focuses on market transformation issues and the technical development of energy efficient fixtures.

\section{EXPERIMENTAL PROCEDURE}

Torchiere research included: 1) characterization of existing halogen sources and torchiere fixtures, and 2) prototyping and characterization of energy efficient CFL torchieres. Characterization of the fixtures included standard photometric measurements (candlepower distribution, fixture efficiency) and power analysis (harmonic distortion, power factor). All photometric testing was conducted on 
seasoned, thermally stabilized lamps with room temperature and voltage conditions at $22^{\circ} \mathrm{C} \pm 0.4^{\circ} \mathrm{C}$ $\left(72^{\circ} \mathrm{F} \pm 1^{\circ} \mathrm{F}\right)$ and at $120 \mathrm{~V} \pm 0.1 \mathrm{~V}$.

A cross-section of halogen torchieres were purchased from several retail chains. These fixtures ranged in price from $\$ 14-\$ 80$ and all included imported $300 \mathrm{~W}$ halogen lamps. Several more expensive domestically produced halogen lamps (bulbs) were also purchased and tested.

\section{CFL Fixture Design}

Several CFL prototypes were constructed using the salvaged fixtures from halogen torchieres. These prototypes included CFLs of all shapes and sizes including quads, triples, circlines, F-lamps and 2D lamps. They contained anywhere from one to four lamps and most could operate at multiple output levels.

A conscious effort was taken to make prototypes that could be realistically manufactured. This often required the use of optical reflector materials with reflectances near $90 \%$ rather than available, yet prohibitively expensive, $98 \%$ reflective materials.

Data from nine of the CFL prototypes is presented here. Prototypes one through five (made with a $43 \mathrm{~cm} / 17$ inch dish) and nine (33 cm/13 inch dish) used two, 32 Watt linear quad lamps (or "FLamps") operated with a single electronic ballast. The linear quad lamps were used because they are small and flat with very high efficacy and lumen output. The design of these prototypes resembled the torchiere shown in Figure 1. Only the reflector design, dish size and position of the lamps changed between these prototypes.
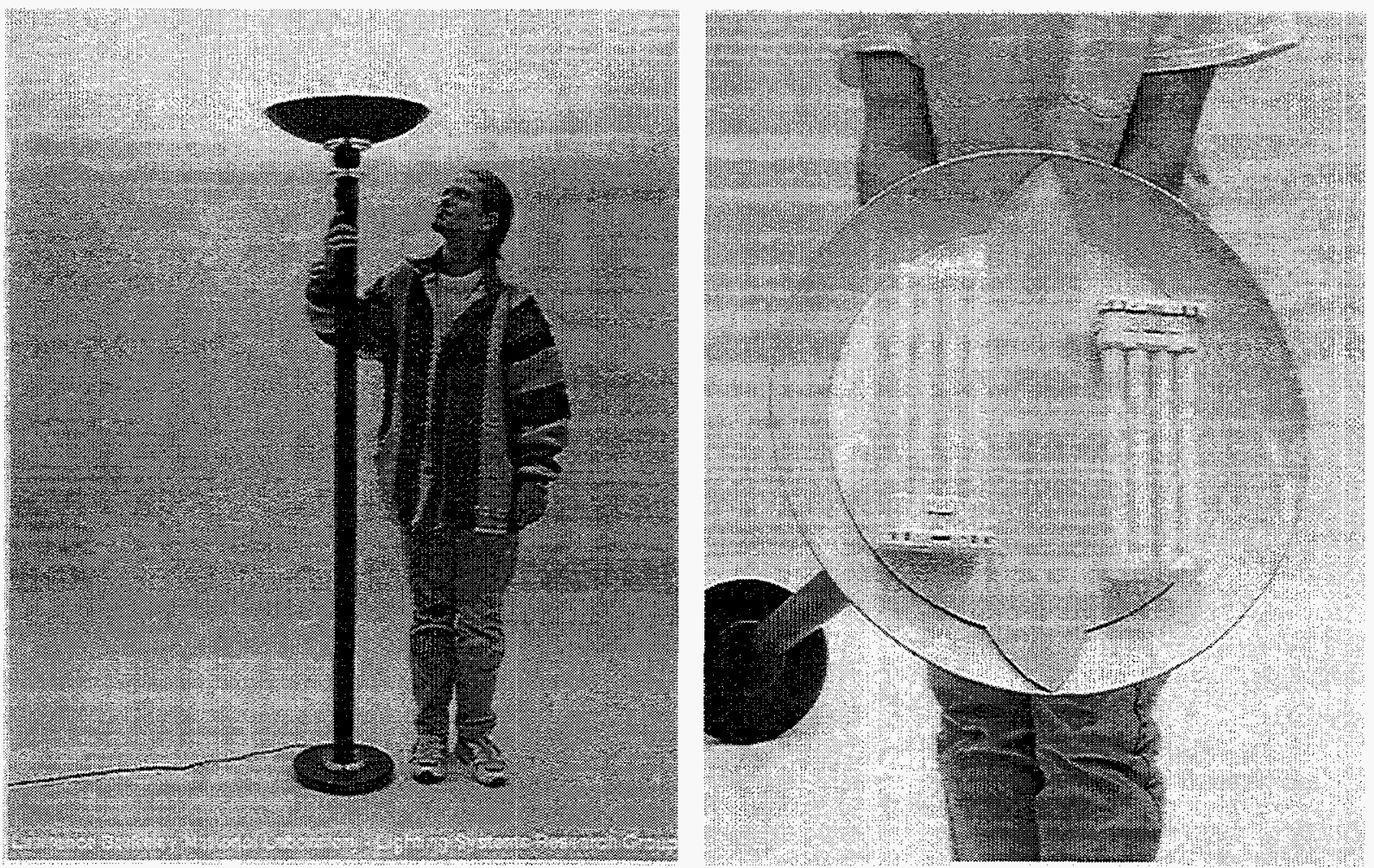

Figure 1. Example of a prototype torchiere design. The reflector and lamp configuration shown on the right is similar to the design of prototypes one through five and nine. 
The optical reflectors for these prototypes were designed to: 1) hide the ballast, 2) prevent direct flux of one lamp from reaching the other, 3 ) provide high fixture efficiency with a shallow dish by placing the lamps near the top aperture, and 4) provide an even ceiling pattern during both one and two lamp operation. Prototypes one, three, five, and nine employed white-painted reflectors with reflectances ranging from 81 to 93 percent. Prototypes two and four used specular reflectors ranging in reflectance from 84 to 98 percent.

Prototype six consisted of a 22 Watt circline lamp located inside a 32 Watt circline. This prototype operated with two separate ballasts and a white reflector. Prototype seven used a 38 Watt 2D lamp with a three-way ballast in a specular reflector with a reflectance of 98 percent. Prototype eight utilized two 32 Watt triple lamps operated by two electronic ballasts in a specular reflector with 98 percent reflectance.

\section{Bare Lamp Lumen Output}

A 2 meter ( 80 inch) integrating sphere was utilized to obtain bare lamp lumen output, power draw and lamp efficacy of the sources.

Halogen: The bare lamps were operated horizontally (as they are in the torchiere fixtures) in the integrating sphere. The lamps were operated on a voltage stabilized line without the torchiere dimming circuits.

CFL: CFLs were operated base up and their ballasts were remote as to not obscure any light. The "base up" lamp orientation yields a more thermally stable lamp operation. This was chosen for bare lamp measurements so that thermal degradation of lumen output in the fixture would register as a decrease in fixture efficiency.

\section{Lumen Output for Dimming}

Halogen: The dimming circuits from a torchiere fixture were removed and added in line with the halogen source in the integrating sphere in order to establish the effect of dimming on source efficacy. Lumen output, total harmonic distortion (THD), and power factor (pf) were recorded at five percent intervals of peak power on several different halogen sources, both domestic and imported. In all dimming experiments, the system was allowed to stabilize for at least 30 minutes between dimming adjustments and measurement.

CFL: CFLs with multi-level ballasts were tested at each level. All testing was performed as described in the "bare lamp lumen output" section above.

\section{Fixture Characterization}

Halogen: Since almost all halogen torchiere fixtures obtained had nearly the same optical geometry (sometimes with very slight differences in the bowl size), the fixture efficiency was only calculated for one fixture. This was done by running a series of tests on a halogen fixture in a computercontrolled swing-arm photo-goniometer (see Figure 2) and comparing the results to those from the halogen lamps previously tested in the integrating sphere. The fixture used contained the same dimming circuit used in the dimming experiments described in the "bare lamp lumen output" section above. During all testing the voltage was stabilized at $120.0 \mathrm{~V} \pm 0.1 \mathrm{~V}$ with the dimmer in the "full on" position. The goniometric experiments yielded candlepower distributions and fixture lumen output and, with the previously obtained bare lamp lumens, fixture efficiency.

CFL: Because all CFL torchiere prototypes varied greatly in design, they were each individually tested in the goniometer. The multi-level fixtures were operated at each level to determine whether the fixture efficiency and candlepower distribution varied with operating level. 


\section{Power Analysis}

Data on power, THD, pf and current crest factor were monitored continuously during goniometric testing by a computer controller linked to a Xitron power analyzer. At the completion of the test, the power analyzer data was averaged and recorded.

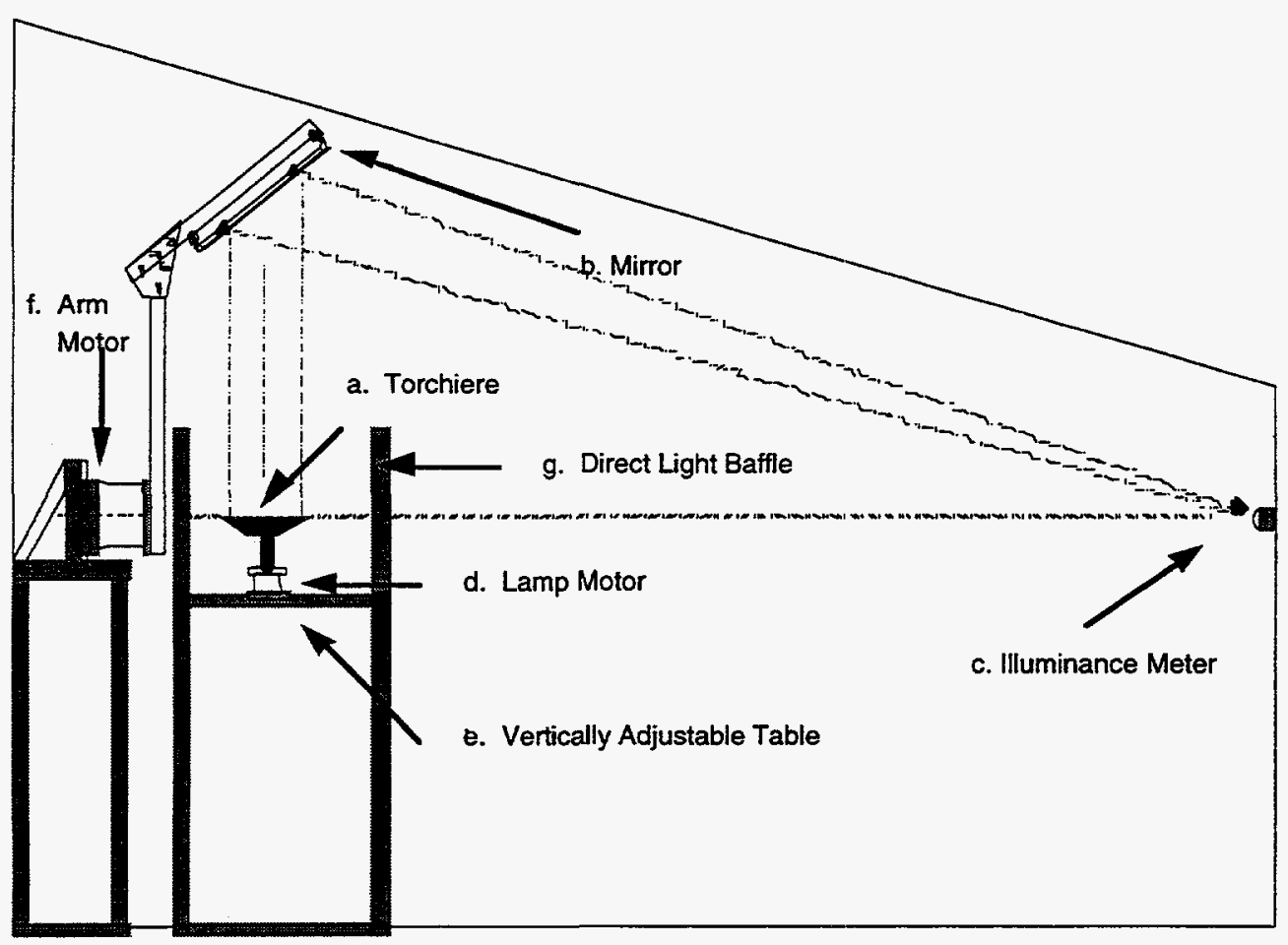

Figure 2. Photo-goniometric Apparatus for Torchiere Testing

\section{RESULTS}

\section{Halogen Torchieres}

Halogen lamps typically have luminous efficacies near $20 \mathrm{LPW}$, higher than standard incandescent lamps, due to their hotter filament. While the manufacturers made no efficacy or lumen output claims on the torchieres we purchased, we expected them to have efficacies near this range. We tested the imported halogen lamps that come with the torchieres as well as more expensive, domestically produced lamps.

\section{Efficacy and Lumen Output}

Table 1 shows the power, light output and efficacy data on both the imported and domestically produced halogen lamps. While the import lamps varied dramatically in both light output and power drawn, they were consistently short of the expected efficacy and lumen output. The average efficacy was found to be $11.6 \mathrm{LPW}$, or more than $40 \%$ less than that of major manufacturers and well below the 15-17 LPW of common household incandescents. 
Table 1. Power, Lumen Output and Efficacy of Typical Halogen Sources

\begin{tabular}{|c|c|c|c|}
\hline Import & Power & Lumens & LPW \\
\hline Lamp 1 & 272.4 & 2710 & 9.949 \\
\hline Lamp 2 & 307.3 & 4413 & 14.36 \\
\hline Lamp 3 & 250.0 & 2722 & 10.88 \\
\hline Lamp 4 & 262.2 & 3282 & 12.52 \\
\hline Lamp 5 & 262.5 & 3239 & 12.34 \\
\hline Lamp 6 & 249.7 & 2477 & 9.920 \\
\hline Lamp 7 & 260.1 & 3010 & 11.57 \\
\hline Lamp 8 & 259.2 & 2934 & 11.32 \\
\hline Average & 265.4 & 3098 & 1167 \\
\hline \multicolumn{4}{|l|}{ Domestic } \\
\hline Lamp 1 & 300.4 & 5410 & 18.01 \\
\hline Lamp 2 & 297.3 & 5607 & 18.86 \\
\hline Lamp 3 & 305.3 & 5817 & 19.05 \\
\hline Average & 301.0 & 5611 & 18.64 \\
\hline
\end{tabular}

\section{Dimming Effect on Halogen Lamp Efficacy}

The dimmers on torchiere fixtures consist of a circuit which distorts the voltage waveform, affecting both lamp efficacy and power quality. These circuits are largely uniform in design with no noticeable difference in the circuits between the high and low end torchiere models, either in appearance or performance.

Figure 3 shows the effect of dimming on halogen source efficacy (average data for a domestic lamp and an import lamp). As can be seen, dimming has a significant non-linear effect on the lamps. For example, when dimmed to $50 \%$ light output, a typical lamp consumed $73 \%$ of peak power. Alternatively, a lamp dimmed to $50 \%$ maximum power only produced $21 \%$ of peak light output.

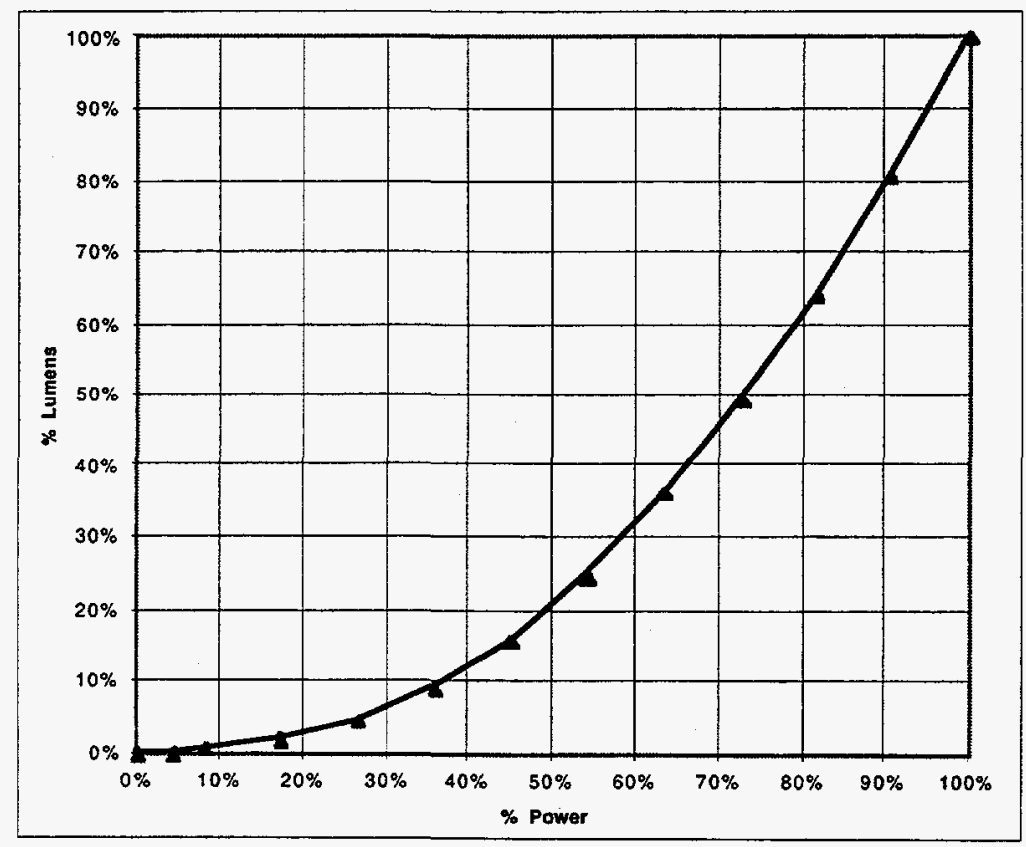

Figure 3. Percent Lumen vs. Percent Power for Dimmed Halogen Sources 


\section{Dimming Effect on Halogen Lamp Power Quality}

Efficacy decreases are not the only drawbacks to halogen dimming; power quality declines significantly with dimming. Table 2 shows the effect of dimming on THD and pf.

Table 2. Dimming Effect on Power Quality

\begin{tabular}{|c|c|c|c|}
\hline Power (\%) & Power (Watts) & \% THD & PF \\
\hline 100 & 262.0 & 5.370 & 0.9993 \\
\hline 95 & 248.9 & 20.31 & 0.9598 \\
\hline 90 & 235.8 & 27.24 & 0.9222 \\
\hline 85 & 222.7 & 33.37 & 0.8861 \\
\hline 80 & 209.6 & 39.80 & 0.8624 \\
\hline 75 & 196.5 & 45.31 & 0.8268 \\
\hline 70 & 183.4 & 50.88 & 0.7895 \\
\hline 65 & 170.3 & 56.48 & 0.7535 \\
\hline 60 & 157.2 & 63.12 & 0.7125 \\
\hline 55 & 144.1 & 69.48 & 0.6724 \\
\hline 50 & 131.0 & 75.41 & 0.6325 \\
\hline 45 & 117.9 & 82.19 & 0.5912 \\
\hline 40 & 104.8 & 89.11 & 0.548 \\
\hline 35 & 91.7 & 95.82 & 0.5004 \\
\hline 30 & 78.6 & 102.1 & 0.4529 \\
\hline 25 & 65.5 & 109.3 & 0.3997 \\
\hline 20 & 52.4 & 117.5 & 0.3458 \\
\hline 15 & 39.3 & 130.0 & 0.285 \\
\hline 10 & 26.2 & 148.4 & 0.2185 \\
\hline 5 & 13.1 & 184.1 & 0.1406 \\
\hline
\end{tabular}

Power quality is a particularly interesting issue when considering the level of concern utility groups have with CFLs that have low pf and high THD. The addition of a large number of these high wattage, low power quality luminaries can have a significant negative impact on a utility.

\section{Fixture Characterization}

Figure 4 shows the candlepower distributions for domestic and imported halogen sources in a typical fixture. These results are averaged data from at least three of each lamp type. The fixture with the domestic lamp has intensities directly above the fixture of nearly 2500 candela, or more than twice that of the import lamps. Obviously because these lamps are of similar geometries and in the same fixture, their candlepower distributions are similar in shape. These fixtures have maximum intensities near apex angles and throw relatively small amounts of direct illumination to lower angles where light would be useful for illuminating far regions of a room.

Table 3 presents the fixture efficiency data for a single torchiere operated with six different halogen sources. The average fixture efficiency of the halogen torchieres is 88.3 percent. Combining this with the source's data from Table 1, the average torchiere with a $300 \mathrm{~W}$ import lamp produces 2736 lumens, while one with a domestic lamp produces 4955 lumens. 


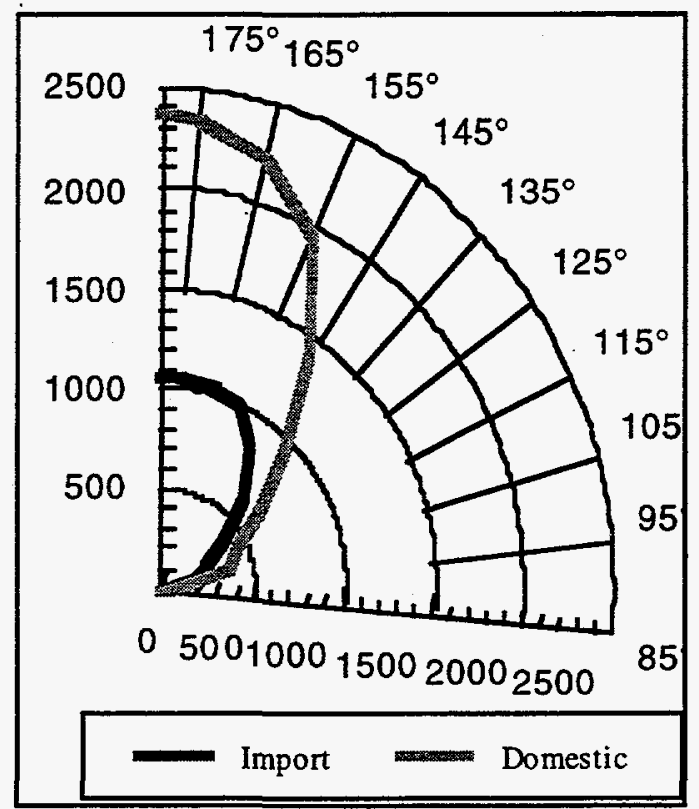

Figure 4. Candlepower Distribution of Halogen Sources in a Torchiere Fixture

Table 3. Fixture Efficiencies of Halogen Torchieres

\begin{tabular}{|c|c|}
\hline Import 1 & 89.5 \\
\hline Import 2 & 88.5 \\
\hline Import 3 & 87.3 \\
\hline Import 4 & 89.6 \\
\hline Domestic 1 & 86.4 \\
\hline Domestic 2 & 88.6 \\
\hline
\end{tabular}

\section{CFL Torchieres}

Numerous CFL torchieres were constructed with a variety of commercially available sources. Torchiere dishes of $33 \mathrm{~cm} / 13$ inches (outside diameter) and $43 \mathrm{~cm} / 17$ inches were used as the fixture casing. These fixtures were initially designed to lumen match the $300 \mathrm{~W}$ import torchieres while attempting to closely mimic their distribution.

\section{Efficacy, Lumen Output, Dimming Effects, and Fixture Efficiency}

Table 4 presents the luminaire lumen output, power, luminaire efficacy and fixture efficiency of 9 unique CFL prototypes. Almost all of these prototypes provide significantly larger lumen packages than the 2736 lumens of the import torchieres, while providing a considerable energy savings. Several of the CFL prototypes even fell within 10 to 20 percent of the lumen output of the high output domestic torchieres. Fixture efficiencies above $90 \%$ were obtained in several prototypes. This was possible because of a combination of advanced optics, a shallow dish, a flat CFL source, and a highly reflective (greater than 90 percent) surface finish. It was found that placing the source as high in the fixture as possible, without producing direct lamp image glare, produced the highest efficiencies.

While dimmers were not utilized, no significant effects were found as a result of the fixtures' multi-level switching. Efficacy, THD, and pf were relatively even regardless of light level. Additionally, fixture optics were designed so that light distribution would remain uniform in multilamp switching fixtures. 
Table 4. Fixture Data for Prototype CFL Torchieres

\begin{tabular}{|c|c|c|c|c|c|c|}
\hline & $\begin{array}{l}\text { Luminaire } \\
\text { Output } \\
\text { (Lumens) }\end{array}$ & $\begin{array}{l}\text { Input Power } \\
\text { (Watts) }\end{array}$ & $\begin{array}{l}\text { Luminaire } \\
\text { Efficacy } \\
\text { (LPW) }\end{array}$ & $\begin{array}{c}\text { Fixture } \\
\text { Efficiency }\end{array}$ & THD & $\begin{array}{l}\text { Power } \\
\text { Factor }\end{array}$ \\
\hline Prototype 1 & 3622 & 61.7 & 58.8 & $77.8 \%$ & $18.37 \%$ & 0.99 \\
\hline Prototype 2 & 3993 & 61.6 & 64.8 & $85.7 \%$ & $18.33 \%$ & 0.99 \\
\hline Prototype 3 & $4226^{6}$ & 61.6 & 68.6 & $90.7 \%$ & $18.33 \%$ & 0.99 \\
\hline Prototype 4 & 4303 & 61.6 & 69.8 & $92.4 \%$ & $18.37 \%$ & 0.99 \\
\hline Prototype 5 & 3943 & 67.5 & 58.4 & $84.6 \%$ & $13.01 \%$ & 0.99 \\
\hline Prototype 6 & 3455 & 59.0 & 58.6 & $90.8 \%$ & $53.94 \%$ & 0.97 \\
\hline Prototype 7 & 2315 & 38.0 & 60.9 & $92.2 \%$ & $n / a$ & $\mathrm{n} / \mathrm{a}$ \\
\hline Prototype 8 & 3658 & 65.4 & 55.9 & $94.3 \%$ & $n / a$ & $\mathrm{n} / \mathrm{a}$ \\
\hline Prototype 9 & 4005 & 61.6 & 65.0 & $83.6 \%$ & $4.58 \%$ & 0.99 \\
\hline
\end{tabular}

\section{Candlepower Distribution}

The prototypes succeeded in lumen matching the halogen torchieres and produced unique candlepower plots as seen in Figure 5. While the prototypes varied greatly from one to the other, in general they produced a much wider distribution than the halogen torchieres. The "hot spot" of the CFL prototypes fell between 1000 and 1300 candela and were able to match the 1000 candela of the import halogen torchieres, but they were no match for the 2400 candela of the domestic lamps. The wider distribution of the prototypes threw much more light into the lower (near horizontal) angles.

While a bright "hot spot" may play an important role in the perception of brightness of the room, it does not necessarily produce appropriate illuminance in a room. This is particularly true across the room from the fixture. The CFL prototypes with their wider distribution likely spread light more effectively through a living space and yield higher illuminance levels throughout the space.
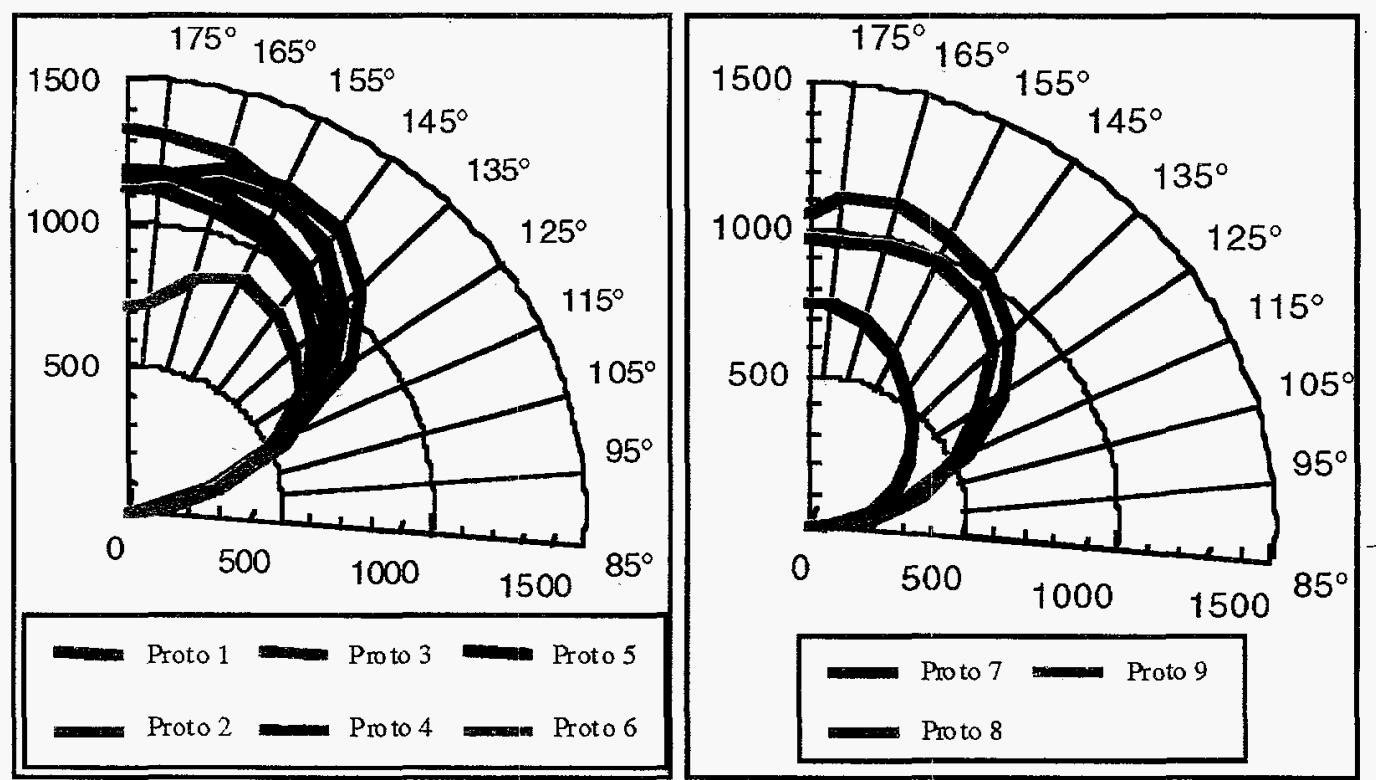

Figure 5. Candlepower Distribution of CFL Prototypes in a 17 inch Torchiere Fixture (left) and a 13 inch Torchiere Fixture (right) 


\section{Energy Use Example During Dimming}

Consider an import lamp running at $265.4 \mathrm{~W}$ (average) with an efficacy of $11.67 \mathrm{LPW}$ (average) which is dimmed to $50 \%$ light output. Suppose this lamp is in a fixture with an efficiency of $88.3 \%$ (average) and is placed in a room with ceiling and wall reflectances of $75 \%$. Assuming a typical light ray bounces off the walls and/or ceiling only once (an underestimate), the delivery efficiency from lamp to task plane or floor is $0.883 \times 0.75$, or $66 \%$. From Figure 4 , at $50 \%$ light output the light is using $73 \%$ of the power. So the $265.4 \mathrm{~W}, 11.67 \mathrm{LPW}$ source becomes a 193.7 $\mathrm{W}, 8.00 \mathrm{LPW}$ fixture with a delivery efficiency of $66 \%$. Thus, this lamp is using nearly $200 \mathrm{~W}$ of energy to deliver light at barely $5 \mathrm{LPW}$.

A $50 \mathrm{~W}$ CFL Torchiere with a source efficacy of $65 \mathrm{LPW}$ and a two-level switch is then put into the same room. Assuming the same fixture efficiency (an underestimate), the delivery efficiency from lamp to task plane or floor is again $66 \%$. But now at $50 \%$ light output, the lamp only uses 25 W. The CFL lamp delivers light to the task plane for $65 \mathrm{LPW} x .66$, or $43 \mathrm{LPW}$, nearly an order of magnitude more efficiently than the halogen torchiere.

\section{CONCLUSIONS}

The experimental photometric and power data indicate that the halogen torchiere is an extremely inefficient energy user. The non-linear dimming control system adds to the already poor efficacy of this lighting system. On a national basis, the sale of halogen torchieres represents one of the largest lighting efficiency and conservation issues to date.

A series of torchiere systems using efficient CFL sources were developed and photometric results indicate that they can provide comparable light output at a fraction of the power. These studies are intended to provide information to manufacturers on how to use efficient sources as a replacement for the 300 Watt tungsten halogen source. This effort is part of an ongoing program that focuses on market transformation issues and the technical development of energy efficient fixtures for residential applications.

\section{ACKNOWLEDGMENT}

This work was supported by the Assistant Secretary for Energy Efficiency and Renewable Energy, U.S. Department of Energy, Office of Building Technology, State and Community Programs, Office of Building Equipment under Contract No. DE-AC03-76F00098.

\section{REFERENCES}

1. Brooks, Andree, "Halogen Hazards: Fire Danger from torchiere-style lamps", San Francisco Chronicle, January 29, 1997, Home Section, p. 5.

2. "Halogen Lamps Burn Bright Despite Yale Ban Over Safety", The New York Times, February 12, 1997, p. A15.

3. Calwell, Chris and Mills, Evan, "Halogen Uplights and Hot Ceilings", Fall 1996, International Association of Energy-Efficient Lighting, no. 16, vol. 5.

4. Calwell, Chris, "Halogen Torchieres: Cold Facts and Hot Ceilings", E Source Tech Update, September 1996.

5. Jennings, Judith, et. al. 1996. "Residential Lighting: The Data to Date" Berkeley, CA: Lawrence Berkeley National Laboratory. 